REVISTA DE ESTUDIOS E INVESTIGACIÓN EN PSICOLOGÍA Y EDUCACIÓN

\title{
Perspetivas sobre a participação da criança no ambiente educativo
}

\section{Perspectives on child participation in the educational environment}

\author{
Sandra Filipe (iD) https://orcid.org/0000-0001-8707-1538 \\ Brigite Silva (D) https://orcid.org/0000-0002-3476-7803 \\ CeiED - Centro de Estudos Interdisciplinares em Educação e Desenvolvimento da Universidade \\ Lusófona de Humanidades e Tecnologia: https://www.ceied.ulusofona.pt/ \\ Lisboa - Portugal \\ CIPAF - Centro de Investigação de Paula Frassinetti: https://www.esepf.pt/apresentacao/ \\ ESEPF - Escola Superior de Educação de Paula Frassinetti: https://www.esepf.pt/ \\ Porto - Portugal
}

Ana Gomes (D) https://orcid.org/0000-0002-2492-3112

CeiED - Centro de Estudos Interdisciplinares em Educação e Desenvolvimento da Universidade Lusófona de Humanidades e Tecnologia: https://www.ceied.ulusofona.pt/

Lisboa - Portugal

CIPAF - Centro de Investigação de Paula Frassinetti: https://www.esepf.pt/apresentacao/

ESEPF - Escola Superior de Educação de Paula Frassinetti: https://www.esepf.pt/

inED - Centro de Investigação e Inovação em Educação da Escola Superior de Educação do

Politécnico do Porto: https://ined.ese.ipp.pt/pt

Porto - Portugal

Correspondencia relativa a este artículo: Brigite Silva - bcs@esepf.pt 


\title{
Resumo
}

A participação das crianças tem vindo a assumir maior destaque nos discursos educativos. No entanto, a ligação entre discursos e práticas nem sempre é consistente. Este artigo incide, assim, sobre perspetivas e práticas de profissionais de educação relativas à participação da criança no processo de ensino-aprendizagem. Com uma metodologia qualitativa, suportada por entrevistas a quatro educadoras de infância e a cinco professoras do 10 Ciclo do Ensino Básico, o estudo tem a finalidade de perceber as suas perspetivas sobre a participação da criança, de que modo a consideram na organização do ambiente educativo e que obstáculos encontram a essa participação. Os dados recolhidos evidenciam a importância reconhecida à participação das crianças no contexto educativo, no entanto, verificam-se diferenças nas perspetivas e nas práticas entre os profissionais. As educadoras de infância valorizam a participação através da escuta das suas motivações e necessidades, considerando a criança como sujeito ativo, apesar de pouco explícita a sua concretização. As professoras do 10 Ciclo do Ensino Básico consideram que a participação do aluno consiste sobretudo na colocação de dúvidas e na resposta ao que é solicitado.

Palavras chave: educação de infância; ensino básico; participação da criança

\begin{abstract}
Children's participation is becoming more prominent in educational discourses. However, the connection between speeches and practices is not always consistent. This article, therefore, examines the conceptions and practices of early childhood and primary school teachers regarding children's participation in the teaching-learning process. The study uses a qualitative methodology consisting of interviews with four early childhood teachers and five first-cycle primary school teachers in order to learn more about their understanding and attitudes towards child participation, how they incorporate child participation into their organisation of the educational environment, and the obstacles to creating a more participatory classroom. The data collected confirmed the importance of child participation in educational settings, but revealed certain differences between the two groups in relation to their attitudes to child participation and teaching practices in this regard. The conception of child participation by early childhood teachers was found to consist of listening to the children's motivations and needs, and treating them as active agents, although this implementation is not very explicit. In the case of first-cycle primary school teachers, pupil participation was viewed mainly in terms of asking and answering questions.
\end{abstract}

Keywords: early childhood education; primary education; child participation 
Ao longo da história, o pensamento educacional predominante foi-se alterando no que diz respeito à conceção de educação, à conceção de aprendizagem, ao papel assumido pelos diferentes intervenientes na ação pedagógica - crianças e docentes - e à organização do ambiente educativo. A predominância de uma conceção que determina do exterior o que a criança aprende, que vê os alunos como recetores passivos de um saber dogmático, produzido por outros e cujos saberes, interesses e necessidades se ignoram, reprimem, ou contrariam a perspetiva que considera a criança ativa na orientação do processo educativo. A participação da criança tem estado mais presente nos discursos educativos contemporâneos (OliveiraFormosinho e Gâmboa, 2011; Oliveira-Formosinho e Formosinho, 2013; Tomás, 2007; Bae, 2016; Sarmento et al., 2019; Fernandes, 2019), consequência do maior reconhecimento da sua agência, da passagem de objeto invisível para sujeito com um estatuto ativo.

Contudo, dos discursos às práticas verifica-se, muitas vezes, uma distância significativa. 0 que é defendido na organização do ambiente educativo e na interação pedagógica, nem sempre se verifica. Neste contexto, é importante ter em consideração que os níveis de participação das crianças podem ser variados, e é necessário atender a que a sua participação não seja meramente simbólica, em que as crianças são consultadas, mas não há repercussões efetivas no contexto (Lansdown, 2010). O reconhecimento da participação enquanto direito da criança encontra-se plasmado no artigo 12. da Convenção dos Direitos das Crianças (UNICEF, 1989) que defende que a criança tem o direito de exprimir livremente a sua opinião e de esta ser tomada em consideração, de acordo com a sua idade e maturidade. Implica ter, assim, a oportunidade de expressar uma opinião, influenciar a tomada de decisões e conseguir mudanças (Lansdown, 2011; O'Kane, 2013).

Uma abordagem participativa, tal como sugerem Graham e Fitzgerald (2010), deve ir mais além de "ouvir as vozes" das crianças. Deve, pois, envolver-se de uma abordagem dialógica onde as interações e relacionamentos são direcionados para o reconhecimento e agência individual das crianças como dos adultos envolvidos. Quando as crianças se movem num ambiente de não participação, estas perdem a possibilidade de dar opiniões, de falar sobre o que pensam, partilhar experiências, medos, vontades e dúvidas. Convidar as crianças ao diálogo possibilitaIhes descobrir, negociar e transformar entendimentos sobre quem são e sobre o seu lugar no mundo (Graham e Fitzgerald, 2010). Abordar a participação das crianças pressupõe, então, uma prática ética (Mascadri et al., 2021) assente no diálogo onde se respeite os seus pontos de vista e opiniões e se reconheça e permita as implicações que esse diálogo possa ter. Implica levar a sério as manifestações das crianças, sendo esta uma forma de se reconhecerem e construírem 
a si próprias, para além de se responder ao respeito pelo exercício da agência individual de cada uma (Mäkitalo, 2016). Quando as crianças são livres para fazer escolhas e para dar a sua opinião, o conflito entre adulto-criança provoca experiências cooperativas e de aprendizagem (Hohmann e Weikart, 2011).

É relevante, neste contexto, não só considerar a existência de uma perspetiva individual, focada na necessidade de dar a cada criança a oportunidade de se pronunciar sobre a tomada de decisões, mas também uma perspetiva sociocolaborativa que defende a ideia do grupo/turma como comunidade de aprendizagem onde as interações assumem predomínio (Oliveira-Formosinho e Gâmboa, 2011; Sousa et al., 2019). No âmbito de uma pedagogia participativa é necessário ter em conta as duas perspetivas, pois "simultaneamente, realiza o ator social em contexto, com formas de participação recíproca, e o ator pessoal em crescimento, que é um sujeito autónomo, com expressão e iniciativa próprias" (Oliveira-Formosinho e Gâmboa, 2011, pp. 31-32). Promover a participação das crianças requer apoiar as iniciativas independentes de cada uma, mas também ajudar a aprimorar as suas competências em situações de grupo, desenvolvendo aptidões sociais, emocionais e de cidadania. O processo educativo tem subjacente uma visão pedagógica sociocêntrica e policêntrica, sendo que "o centro do ato educativo é uma rede intrincada de relações à qual a criança pertence" (Vasconcelos, 2015, p. 35).

Neste sentido, importa que os profissionais de educação observem as manifestações (verbais e não-verbais) das crianças e as interpretem, considerem a escuta e a tomada de decisão na prática quotidiana para que as crianças aprendam que o que dizem ou expressam é tomado em consideração (Clark, 2005). As crianças são capazes de demonstrar as suas opiniões e ideias, no entanto, esta capacidade é influenciada pelo contexto e, sobretudo, pelo modo como os adultos facilitam a expressão e apoiam a sua participação (Sheridan e Pramling Samuelsson, 2001; Veiga e Ferreira, 2017). A criança aprende a participar e a ser protagonista ativa da sua vida e aprendizagem se tiver oportunidade de experimentar processos de participação e de decisão democrática e, consequentemente, os efeitos das decisões. Como afirmam Moraes et al. (2017), ter voz e ter protagonismo implica experienciar diariamente a possibilidade de colaborar nas tomadas de decisão, no planeamento, organização e vivência do quotidiano.

Dada a experiência acumulada na supervisão da Prática de Ensino Supervisionada em contexto de Educação de Infância e de 1 ํ Ciclo do Ensino Básico na formação inicial dos educadores/professores, percecionamos, à luz dos referentes teóricos, que a participação das 
crianças nos contextos educativos pode se efetivar em diferentes vertentes, nomeadamente na organização do grupo, dos espaços e materiais, nas rotinas, na planificação, na avaliação, entre outras.

A organização dos espaços e materiais deve partir do que o educador/professor observa e escuta da criança, tentando responder às suas necessidades e interesses, criando espaços que potenciam aprendizagens diversificadas e interações. Na rotina diária a criança deve também encontrar lugar para expressar os seus propósitos, ouvir e colaborar com outros e colocar em ação os seus planos. Proporcionar momentos de planificação com a criança "dá à criança poder para se escutar e para comunicar a escuta que fez de si" (Oliveira-Formosinho e Gâmboa, 2011, p. 33). O papel do adulto, aqui, é o de alguém que cria possibilidades para que a criança se escute a si mesma e defina as suas intenções e interesses, que considera os propósitos das crianças e que é gerador de negociações quando a planificação implica decisões grupais.

A negociação é perspetivada como uma solução para integrar opiniões, aprender uns com os outros e para aprender a chegar a consensos, sendo "um instrumento de participação que afasta ainda mais a perspetiva construtivista da perspetiva tradicional" (Oliveira-Formosinho e Gâmboa, 2011, p. 33). É pela prossecução de compromissos assumidos que a criança também aprende a exercer responsabilidades e deveres. Esta é, inevitável e pertinentemente, outra face de uma educação pelos direitos. A participação da criança na gestão da dinâmica social do grupo/turma e do currículo constitui ainda uma opção que potencia a criação de climas democráticos e o sentido de pertença. A utilização de estratégias do grupo/turma constituem meios encontrados em algumas abordagens pedagógicas para responder a uma perspetiva democrática e sociocêntrica da aprendizagem. A avaliação é igualmente uma dimensão importante da função do educador/professor que beneficia com a participação das crianças. Neste âmbito, Silva e Craveiro (2014) afirmam que:

A tarefa do educador de desafiar e de envolver a criança no processo de ensinoaprendizagem e na (auto)avaliação favorece, por consequência, na criança o desenvolvimento de atitudes de diálogo crítico, de responsabilidade, de compromisso voluntário e persistência na concretização das suas aspirações e objetivos. (p. 36).

Algumas abordagens pedagógicas, como por exemplo a metodologia de trabalho de projeto, incentivam as crianças a escolherem as atividades que elas próprias podem desenvolver e orientar, tornando-se as protagonistas do decurso da sua própria aprendizagem. Sustentamse na motivação intrínseca da criança, partindo do pressuposto do interesse desta e na crença de que incentiva uma aprendizagem mais significativa porque possibilita o poder de decidir 0 que quer fazer. 
No desenvolvimento de uma pedagogia participativa, as crianças são vistas como possuidoras de diversos saberes e capacidades e são estimuladas a colocar questões, a investigar, a experimentar, a partilhar, a chegar a consensos, a assumir responsabilidades, a avaliar, etc. Essas habilidades estão enquadradas também no Perfil de Competências à saída da Escolaridade Obrigatória (Despacho n. 6478/2017) onde se pressupõem, como referências, a liberdade, a responsabilidade, a valorização do trabalho, a consciência de si próprio, a inserção familiar e comunitária e a participação na sociedade que nos rodeia.

Resumindo, os contextos educativos promotores da participação das crianças são locais onde estas têm de ser ouvidas, incentivadas e apoiadas na expressão das suas opiniões, envolvidas nos processos de tomada de decisão e tidas em consideração para compartilharem o poder e a responsabilidade pelas decisões.

\section{Método}

A investigação realizada, enquadrada num paradigma de investigação qualitativa, procurou perceber como educadores de infância e professores do 1을 Ciclo do Ensino Básico (1으 CEB) entendem e valorizam a participação da criança no processo de ensino-aprendizagem, de que modo consideram a participação da criança na organização do ambiente educativo e que obstáculos encontram a essa participação.

\section{Participantes}

Esta investigação envolveu uma amostra de conveniência, constituída por orientadores cooperantes responsáveis por grupos/turmas onde decorre a Prática de Ensino Supervisionada num mestrado de Formação de Professores.

A Tabela 1 apresenta a idade e o ano de escolaridade das crianças ao encargo das educadoras e professoras quando foram entrevistadas.

\section{Tabela 1}

Idade e ano de escolaridade das crianças ao encargo dos profissionais de educação

\begin{tabular}{lclc}
\hline Educadoras de infância & Idades das crianças & Professoras do 1o CEB & $\begin{array}{c}\text { Idade das crianças/ Ano } \\
\text { de escolaridade }\end{array}$ \\
\hline Educadora 1 (Ed. 1) & 5 anos & Professora 1 (Prof. 1) & 9 anos/4ㅇ ano \\
Educadora 2 (Ed. 2) & 3 e 4 anos & Professora 2 (Prof. 2) & 8 anos/3o ano \\
Educadora 3 (Ed. 3) & 3 e 4 anos & Professora 3 (Prof. 3) & 9 anos/4o ano \\
Educadora 4 (Ed. 4) & 5 anos & Professora 4 (Prof. 4) & 7 anos/2o ano \\
& & Professora 5 (Prof. 5) & 7 anos/2o ano \\
\hline
\end{tabular}


As participantes foram nove profissionaisde de educação, sendo elas quatro educadoras de infância, de uma Instituição Particular de Solidariedade Social, e cinco professoras do 1 을, de uma escola da rede pública, com idades compreendidas entre os 37 e os 52 anos de idade, e com tempo de serviço, entre os 11 aos 21 anos. Relativamente à formação dos participantes, três educadoras de infância são licenciadas e uma possui bacharelato e complemento de habilitação na área das expressões, as professoras do 1ํㅡㄹ SẼo licenciadas.

\section{Instrumento}

Os dados foram recolhidos através de entrevista semiestruturada (ver Apêndice - Guiões das Entrevistas). O guião de entrevista, tendo em vista responder aos objetivos da investigação, previa como dimensões a caracterização académica e socioprofissional dos participantes e a conceção e concordância sobre: a participação da criança no processo de ensino aprendizagem; benefícios da participação da criança a nível individual e grupal; possibilidades e formas de participação da criança e; obstáculos à participação da criança.

Os resultados são parte de uma investigação mais aprofundada e pretendem apoiar a melhoria dos contextos na construção de reflexões sobre a participação das crianças.

\section{Procedimentos}

Os participantes foram selecionados e informados dos objetivos e características do estudo, tendo sido pedido o seu consentimento informado. Após uma revisão da literatura, foram definidos os objetivos da investigação, elegido e estruturado o instrumento para a recolha de dados. Posteriormente à aplicação presencial e registo áudio das respostas, procedeu-se à transcrição das entrevistas e consequente análise.

\section{Resultados}

O facto de o estudo se debruçar sobre dois níveis educativos diferentes, os dados recolhidos permitiram perceber, em alguns aspetos, especificidades de cada contexto.

\section{Perspetivas sobre o que é a participação da criança}

Quando interrogadas sobre como entendem a participação das crianças, três das educadoras de infância referiram que a participação da criança consiste no envolvimento da criança na sua aprendizagem, nomeadamente na “(...) demonstração de interesse, de vontade de saber e do papel ativo na sua aprendizagem" (Ed. 1), na "(...) forma direta da criança intervir no seu processo de aprendizagem” (Ed. 2), na consideração de que a criança é “(...) um agente 
que intervém no seu processo de aprendizagem" (Ed. 3). Contudo, a Ed. 4 vai mais longe e afirma que "A participação da criança é quando ela é capaz de estar física e psicologicamente envolvida numa atividade" e ainda acrescenta que esta pode participar "(...) através das palavras ou através de ações concretas" (Ed. 4). Quanto às professoras do 10 CEB, quatro (Prof. 1, 2, 3 e 4) referiram que a participação do aluno consiste em intervir na aula, responder a perguntas e colocar dúvidas:

“(...) participa de uma forma adequada dentro do contexto de sala de aula e dentro daquilo que estamos a falar, de uma forma organizada" (Prof. 1);

"É participar em tudo que nós lhes damos a conhecer, em todos os conteúdos, nos recreios, dentro da sala de aula, fora da sala de aula" (Prof. 2);

“(...) intervêm adequadamente, respondem sempre que é pedido, expõem as dúvidas" (Prof. 3);

"É eles colaborarem nas perguntas que são feitas, nas perguntas que a professora faz. Quando estamos, por exemplo, a trabalhar um texto, eles, autonomamente, questionarem, tirarem dúvidas" (Prof. 4).

A Prof. 2 ainda salienta a participação fora da sala de aula e a Prof. 5 afirma que não há apenas um tipo de participação, mas sim diversos tipos, podendo esta “(...) ser mais ativa ou menos ativa, pode ser oral, pode até ser só de expressões (...)".

Através das respostas dadas, é possível verificar que, para as educadoras de infância, a participação da criança se liga ao facto de esta ser ativa no seu processo de aprendizagem, transparecendo a participação mais associada ao envolvimento ou implicação em determinada atividade, o que não corresponde à conceção de participação envolvendo uma "escuta" da criança de forma a poder influenciar o decurso dos acontecimentos.

Para as professoras do 10 CEB a participação da criança baseia-se numa participação com a função de colocar dúvidas e responder ao que the é pedido, onde o papel do aluno consiste, sobretudo, em seguir as instruções do professor. As cinco professoras do 10 CEB defendem a participação das crianças no processo de ensino-aprendizagem justificando-a com o facto de ser possível perceber o que o aluno sabe, quais as suas dúvidas e promover a sua oralidade:

"É uma das formas de muitas vezes, percebermos aquilo que eles sabem, (...) por exemplo, há alunos em que a parte oral é muito melhor que a parte escrita" (Prof. 1); "Porque é assim que nós conseguimos saber até que ponto é que eles sabem ou não sabem o que nós estamos a dar" (Prof. 2);

"Porque é fundamental eles também darem a sua opinião, ouvi-los e saber as dúvidas que têm e o que pensam acerca dos vários assuntos" (Prof. 3);

"Porque também desenvolve a oralidade" (Prof. 4);

"Acho que isso é importante para eles exporem, para tirarem dúvidas, para que possa ser regulada a sua participação, a sua oralidade, a sua participação escrita" (Prof. 5); 
Para as profissionais, o facto de as crianças "participarem" facilita perceber o que sabem e quais as suas necessidades educativas. Por outro lado, veem a participação como um modo de favorecer também a própria aprendizagem de conteúdos. Transparece aqui mais uma associação ao processo avaliativo do que à aquisição de competências e atitudes de participação.

As entrevistadas também apontaram benefícios da participação da criança no processo de ensino-aprendizagem, ressaltando a motivação e a capacidade de expressar necessidades, interesses e emoções, bem como a criação de relações. A motivação é considerada um fator importante para a participação da criança, na medida em que a pode levar a querer saber mais, a ficar "(...) mais predisposta para adquirir novos conhecimentos" (Ed. 2). No que diz respeito às capacidades de expressão, é referido que "Facilmente a criança consegue comunicar, interrogar e expor as suas necessidades e interesses" (Ed. 1), “(...) permite-lhe alargar os seus conhecimentos, exteriorizar emoções e sentimentos, interiorizar e alargar novas aprendizagens, criar relações de proximidade com os outros" (Ed. 4). As professoras do profissionaisde educação CEB apontam ainda como benefícios uma melhor atenção, o esclarecimento de dúvidas, a demonstração dos conhecimentos, a facilitação das interações entre a turma, a obtenção de um feedback e a possibilidade de poderem observar um modelo de participação:

"Se está a participar, está a absorver, está a captar e está com atenção àquilo que estamos a falar" (Prof. 1);

"Os benefícios é eles conseguirem tirar as dúvidas que têm, é nós conseguirmos compreender quais são e eles porem em prática realmente aquilo que sabem ou não" (Prof. 2);

"Podemos nós, também, esclarecê-los melhor (...) saber como agir em determinadas situações e eles podem também ter melhores resultados" (Prof. 3);

"(...) sentirem-se, se calhar, mais ligados à turma, haver mais interação entre eles" (Prof. 4);

“(...) eles saberem se está certo, se está errado” (Prof. 5).

\section{Possibilidades e formas de participação das crianças}

Relativamente à participação da criança na organização do espaço e materiais, afirmam que "Pode ser alterado e normalmente esta mudança implica uma avaliação e reflexão com o grupo de crianças” (Ed. 1) e, desta forma, as crianças “(...) manifestam os seus interesses em relação ao espaço-sala" (Ed. 3). Nem todas as professoras contam com a participação da criança nesta dimensão, uma vez que "É uma turma especial, uma turma com algumas características em que não podem ser eles a decidir (...) poderíamos, eventualmente, negociar, mas às vezes não dá para negociar." (Prof. 1). Por sua vez, algumas das professoras afirmaram que "São eles 
que distribuem normalmente o material, que o recolhem, que arrumam a sala. Também colaboram na forma como a sala está organizada, dão a sua opinião" (Prof. 3) explicando que

"No início do ano estabeleci que cada um tivesse uma função. (...) foram eleitos o delegado e subdelegado, e esses meninos iam buscar os materiais, os manuais, distribuir os porta-lápis (...) depois, todos os dias, por norma, o lanche da tarde é distribuído por grupos diferentes." (Prof. 4).

Pelos comentários das professoras, percebe-se que muitas vezes a participação é associada à execução de funções definidas pelo adulto.

Contudo, por vezes a participação na organização do espaço não é tão fácil, pois "São salas de aula muito pequenas (...) mas em termos de organização de material, eles fazem-no em grupo e regulam-se pelas regras dos materiais, de recolha e de entrega" (Prof. 5). Das entrevistadas, apenas duas educadoras ( 1 e 3 ) referiram a participação da criança na organização do espaço e dos materiais. As professoras do 1을 CEB mostraram-se mais seguras no que diz respeito à participação do aluno, nesta dimensão, especificando de que forma é que esta acontece, ou não, e as razões.

No que diz respeito ao tempo, as educadoras de infância manifestaram maior flexibilidade na gestão deste; já as professoras do 1을 CEB afirmam terem um tempo estipulado para as tarefas devido à incapacidade dos alunos para o gerir:

"Sou eu que tento gerir o tempo, porque por eles estaríamos a conversar o dia inteiro" (Prof. 1);

"Demoram muito tempo a fazer as coisas, ainda têm muita dificuldade na gestão do tempo" (Prof. 2);

"Tem que haver um tempo, se bem que alguns, são um bocadinho mais lentos" (Prof. 3).

"Se for uma atividade que seja livre também não vou estabelecer um horário previsto" (Prof. 4).

A idade também pode determinar a maior ou menor flexibilidade no que ao tempo diz respeito, pois

"Quando são mais velhos, sim pode haver uma interação maior entre o professor e aluno e entre a aula desejável e a aula que tem de ser, porque eles aí já entendem as necessidades. Com os mais novos ainda é preciso regular, tem de haver um fio condutor (...), tem que ser muito mais rígida" (Prof. 5).

É possível perceber que a gestão do tempo é feita maioritariamente pelo adulto, muito devido ao facto de entenderem que os alunos ainda não são capazes de o gerir de forma autónoma, indo ao encontro de uma pedagogia que deixa o aluno à margem de certas tomadas de decisão.

Relativamente às interações, nomeadamente quando há alguma situação conflituosa, afirmam ser necessária a intervenção do adulto, pois "Ainda é uma idade muito pequena, em 
que eles precisam da atenção e de ser chamados à razão" (Prof. 1), "Procuram bastante o adulto" (Prof. 2) e "Vêm fazer mais queixa, (...) depois tento fazer-Ihes ver que são coisas que não se deve fazer" (Prof. 4). Contudo, também são enumeradas estratégias de resolução de conflitos, como a criação de um momento onde o conflito “(...) é debatido em grande grupo e também ouvem a opinião uns dos outros e temos de chegar a um consenso todos" (Prof. 3), ou deixar que sejam os alunos a resolver os seus conflitos pois há o reconhecimento de “(...) que é importante que sejam eles a resolver. E quando há algum problema com a turma, isso sim, tem de ser organizada uma assembleia de turma" (Prof. 5). As entrevistadas verbalizam usar estratégias que fomentam a autonomia do aluno na gestão e resolução de conflitos, embora com a intervenção do docente.

Quanto à planificação, é afirmado que:

"[o educador] deve também ajudar a criar estratégias, isto é o modo como [a criança] gostaria de realizar determinada atividade" (Ed. 2);

"As crianças planificam diariamente com a Educadora" (Ed. 3);

"O educador deve planificar as atividades com as crianças para que através das suas necessidades e interesses elas sejam capazes de organizar os espaços e os tempos criando e desenvolvendo projetos que Ihes permitam crescer a todos os níveis" (Ed. 4); "Se há um projeto, normalmente é debatido com eles, ou surge por alguma questão que se levante, ou porque eu vejo que a turma precisa de alguma coisa" (Prof. 1).

Algumas professoras afirmam não fazer a planificação com os alunos, exceto “(...) quando são atividades mais lúdicas (...). Nas atividades do dia-a-dia, na planificação diária normalmente não" (Prof. 1). Há profissionais que dão a conhecer aos alunos o que irão fazer no próprio dia:

"Eu digo, agora vamos trabalhar este tema, agora é estudo do meio e depois faço uma abordagem, primeiro oral, introduzo um tema que vá ao encontro do tema que vai ser abordado, para eles decifrarem que tipo de assunto vai ser trabalhado (....)" (Prof. 4); "Normalmente eles sabem os temas que temos de trabalhar e como é que vai ser gerido. Se não é durante a semana, no início do dia, logo de manhã, eles sabem, à partida, o que é que vamos tratar. E volta e meia, também propõem. Há sempre um dia em que eu deixo que sejam eles a propor e a sugerir atividades" (Prof. 3).

No entanto, há quem afirme que "Faço a planificação, mas para mim, para eles eu não ponho a planificação no quadro" (Prof. 2).

Mais uma vez, a idade é indicada como um dos fatores que levam as docentes a tomar esta decisão, pois “Quando são mais velhos, a planificação, e mesmo os horários, são feitos com o acordo deles, havendo sempre uma base de trabalho. Com os mais pequeninos não. É-lhes apresentado o que é preciso fazer" (Prof. 5).

No que respeita à avaliação, há quem afirme que "Após a realização das atividades esta [a criança] deve ser capaz também de explicar a forma como correu" (Ed. 2). 
Para algumas professoras a avaliação é feita com a participação dos alunos:

"Faço sempre com eles, isso sim, faço em todos os aspetos, comportamento, aprendizagem (...). Acho que é importante eles realmente terem a noção se sabem ou não e como se comportam" (Prof. 2);

"Eles fazem, também, autoavaliação." (Prof. 3).

A idade em que os alunos se encontram também parece influenciar este processo, pois nas faixas etárias mais baixas "A avaliação é um bocado complicada, porque nesta fase eles ainda são um bocado egocêntricos, ainda não conseguem muito fazer uma auto e heteroavaliação. Embora já sejam muito críticos com a avaliação que lhes damos (...)” (Prof. 5). Já com alunos mais velhos o processo é mais simples, pois "Alguns já conseguem, nesta fase, começar a sair de si e comparar-se com os pares. Portanto, a avaliação aí já é mais regulada, já se pode discutir" (Prof. 5).

Relativamente à organização do grupo/turma, todas as professoras afirmam serem os alunos a escolher os responsáveis de turma (delegado e subdelegado). No que diz respeito à escolha dos grupos de trabalho, o mesmo não acontece "Se não depois há muita conversa e pouco trabalho. Tento distribuí-los de forma igual para que não haja nem grupos com mais fracos, nem grupos com muito bons, tento que sejam mais heterogéneos" (Prof. 3). Um outro fator é a tendência que os alunos têm para confundir os grupos de amizade com os grupos de trabalho presente quando afirmam

"Esses meninos queriam estar sempre juntos e eu comecei a ver que eles não trabalhavam bem assim, porque era um grupo que desde a educação pré-escolar que se conheciam e então vi que não iria funcionar bem e decidi que os separava, não iam ficar juntos" (Prof. 4).

Assim sendo, a formação de grupos "Tem de ser sempre muito orientada se queremos ter sucesso. Eles não conseguem fazer grupos de trabalho, fazem grupos de amizade e confundem uma coisa com a outra e, portanto, precisam ainda de muita orientação" (Prof. 5). Mas, também, os diferentes ritmos de aprendizagem podem influenciar a decisão das docentes, pois "Por uma questão de estratégia, nós temos uma turma muito especial, em que temos alunos muito bons e alunos muito fracos, portanto, por uma questão de organização, de que o grupo fique mais heterogéneo, no fundo" (Prof. 1). Apenas uma professora referiu o facto de ainda não ter feito nenhum trabalho de grupo, mas afirmou considerar “(...) importante eles trabalharem e saberem trabalhar em grupo" (Prof. 2). É possível constatar que a participação da criança na organização do grupo/turma ainda é bastante limitada pelo adulto, sendo as justificações suportadas em razões relacionadas com assegurar determinadas condições pedagógicas (grupos heterogéneos), com a inaptidão para as crianças se organizarem de modo a responderem aos objetivos propostos. 
Desta forma, parece ser possível inferir que, sobre a participação das crianças em diferentes dimensões da intervenção pedagógica, as respostas das educadoras de infância circunscreveram-se à organização do espaço e materiais, às atividades e avaliações das mesmas, não especificando claramente a forma como esta decorre. Perceciona-se um discurso mais consentâneo com o desejável, mas, na maioria das vezes, sem expressão prática.

No âmbito do 10 CEB, segundo o entendimento que as entrevistadas têm acerca da participação, esta emerge associada ao processo de avaliação das aprendizagens. Foi possível verificar que a opinião dos alunos não é tida em consideração em vários aspetos, nomeadamente na planificação, organização de grupos e gestão de tempo, suportando-se em justificações relacionadas com a idade dos alunos, com a incapacidade de fazerem uma gestão autónoma do tempo, e com os diferentes níveis de aprendizagem.

\section{Obstáculos à participação da criança no processo de ensino-aprendizagem}

Quanto aos obstáculos que as profissionais encontram para a participação das crianças, as educadoras de infância mencionaram a timidez, pois "Por vezes é preciso incentivar pois há muitas crianças que são tímidas, que não gostam de se expressar em grande grupo" (Ed.1); o não conhecimento quer por parte da educadora em relação ao grupo, quer por parte do grupo em relação à educadora (Ed. 3); as interrupções a meio das atividades, bem como a escassez de recursos tecnológicos com o acesso à internet são também mencionados por uma educadora (Ed. 4).

Os obstáculos mencionados pelas professoras do 1ㅇ CEB são: a facilidade com que os alunos mudam de assunto, pois “Ás vezes eles não têm noção que estamos a falar desta matéria, mas eles vão buscar já outra coisa e falam e mudam a conversa para não sei onde, (...) eles nem sempre canalizam bem a informação, se calhar é o maior obstáculo" (Prof. 1); a falta de organização ao participar, o facto de as turmas serem muito grandes "Os obstáculos é serem muitos alunos, (...) muitas vezes os próprios colegas não deixam que eles consigam participar corretamente" (Prof. 2); a organização do tempo, pois "Ás vezes é uma questão de tempo, mas têm que se organizar de forma a que todos possam participar. Se não é no mesmo dia, porque as turmas são grandes, é fazer com que uns participem num dia e depois os outros, noutro dia" (Prof. 3); e também a timidez do aluno, tendo sido referido que há alunos que "Mesmo que até possam saber, por medo de errar, ou vergonha de os colegas fazerem, dizerem alguma coisa, não participam, sentem-se inibidos" (Prof. 4).

As entrevistadas apontam obstáculos que dizem respeito a aspetos intrínsecos das crianças, como a timidez e alguma dificuldade em se organizarem na forma como participam, e 
condicionamentos das circunstâncias como o tamanho dos grupos/turmas, a falta de recursos tecnológicos para apoiar a pesquisa e consequente resposta aos interesses das crianças, a escassez do tempo necessário à participação de todos e a interrupção das atividades ao longo da rotina diária.

\section{Considerações Finais}

Apesar de os direitos de participação das crianças serem teoricamente reconhecidos, pelo discurso das entrevistadas, não se percecionam plenamente assumidos, nem totalmente clarificados quanto à "forma" de ocorrência, na interação quotidiana entre educadores/professores e crianças e no modo como organizam o ambiente educativo. Os profissionais de educação podem não ter a intenção de não escutar as crianças, mas, nos seus discursos, acabam por revelar a ausência de uma efetiva participação na tomada de consideração dos pontos de vistas destas. O próprio entendimento acerca do que é participação, manifestado por estes profissionais, ignora que esta acontece num contexto e interações permeáveis à mudança do decurso dos acontecimentos. A provável imagem de criança que manifestam possuir (incapazes, com dificuldades em se organizarem e interagirem em grupo) pode determinar o modo como as consideram. Educadores/professores que as veem como sujeitos dependentes, tendem a agir de forma mais dirigida e educadores/professores que as consideram como agentes competentes, que possuem uma perspetiva construtivista da aprendizagem, proporcionam e apoiam a participação das crianças (Berthelsen e Brownlee, 2005).

Mediante os dados recolhidos com este estudo, é possível constatar que as profissionais de educação reconhecem que é benéfico que as crianças participem no contexto educativo, mas não transparece a apropriação clara de uma pedagogia onde educadores e crianças, mais do que coatores da aprendizagem, consciencializam e praticam atividades e projetos "através do pensar, fazer e refletir em companhia" (Oliveira-Formosinho e Formosinho, 2013). Percecionamos, na generalidade, diferenças entre as perspetivas das educadoras de infância e das professoras do 1을 AEB. Através da verbalização das educadoras de infância, estas manifestam procurar integrar a criança no processo de ensino-aprendizagem através da escuta das suas motivações e necessidades, considerando a criança como sujeito ativo no processo educativo. Contudo, fica pouco explícito que esta preocupação se traduza numa participação ativa e efetiva por parte das crianças. Quanto às professoras do 1을 CEB, foi possível perceber no seu discurso que a participação do aluno no processo de ensino-aprendizagem consiste 
sobretudo na colocação de dúvidas e na resposta ao que é solicitado pela professora. A opinião dos alunos evidencia-se pouco considerada na planificação, organização de grupos e gestão de tempo.

O entendimento da participação como uma vivência que se efetiva num processo social que envolve interação, manifestação de ideias, opiniões, escolhas e negociações (Tomás, 2007) é mais explícito nos comentários das educadoras de infância. Mas, a real compreensão de que "participar significa influir diretamente nas decisões" (Tomás, 2007, p. 47) encontra pouca expressão nos comentários de todas as profissionais.

Neste sentido, percebe-se que, quanto às possibilidades de participação manifestadas, predomina uma participação de caráter consultivo, que é dirigida e controlada pelos adultos (ainda que havendo o reconhecimento dos benefícios da participação das crianças), mais do que de caráter colaborativo ou da iniciativa destas.

As profissionais são unânimes em afirmar benefícios diretos da participação tanto para a própria criança, como para as próprias profissionais por thes permitir perceber melhor as necessidades e interesses destas e, assim, facilitar a adequação da intervenção educativa. No entanto, não exprimem a importância da participação enquanto direito das crianças, nem enquanto meio de promoção de um ambiente democrático e de desenvolvimento de competências pessoais e sociais.

Entretanto apontam obstáculos que dizem respeito às próprias características das crianças (como a timidez e dificuldade na interação social), o número de crianças no grupo/turma, o tempo e os recursos para aceder rapidamente à informação solicitada pelas crianças.

Este estudo evidencia sobretudo que os profissionais de educação nem sempre têm um entendimento adequado de como deve ser encarada a participação da criança, como já referido anteriormente, na perspetiva de que pode influenciar as decisões no processo de ensinoaprendizagem (Tomás, 2007; Fernandes, 2019). Consideramos fundamental que a participação da criança no ambiente educativo seja promovida desde cedo através de práticas simples da vida cotidiana e da (re)significação dos discursos adulto/criança promovendo processos autónomos e de participação genuína no reconhecimento do trabalho a partir do outro.

É relevante que os profissionais de educação sejam formados para proporcionarem contextos educativos transformadores que assegurem o direito à participação das crianças, considerando a valorização da livre iniciativa e do brincar enquanto respeito pela forma mais natural de participação, onde sejam incentivadas a se expressarem, onde as suas opiniões sejam 
ouvidas, respeitadas e consideradas nas tomadas de decisões, onde sejam apoiadas na reflexão e no desenvolvimento dos seus planos, onde possam assumir e exercer responsabilidades e onde aprendam, também, a ouvir e a aceitar as opiniões e vontades de outros.

A participação ativa da criança no ambiente educativo, além da visão social e da garantia do direito à participação também tem a ver com o desenvolvimento da pessoa na sua essência, no favorecimento e potenciação de capacidades e competências para estabelecer vínculos e interações consigo mesmo e com os outros, desenvolvendo competências socio-emocionais, o que remete para a necessidade de uma escola que experimente mudanças na perceção sobre o processo de ensino e aprendizagem (Echeverría et al., 2020, p.180).

\section{Referências}

BAE, Berit (2016). O direito das crianças a participar - desafios nas interações do quotidiano. Da Investigação às Práticas, 6 (1), 7-30. https://doi.org/10.25757/invep.v6i1.107

BERTHELSEN, Donna, \& BROWNLEE, Joanne (2005). Respecting children's agency for learning and rights to participation in child care programs. International Journal of Early Childhood, 37, 49-60. https://doi.org/10.1007/BF03168345

CLARK, Alison (2005). Ways of seeing: Using the Mosaic approach to listen to young children's perspective. In Alison Clark, Anne Tine Kjørholt \& Peter Moss (Eds.) Beyond Listening: Children's Perspectives on Early Childhood Services (pp. 29-49). Bristol: Policy Press. https://www.sagepub.com/sites/default/files/upm-binaries/43997_9781446207529.pdf

Despacho n. 6478/2017 de 26 de julho. Diário da República n. 143/2017, Série II de 2017-0726. Lisboa. Gabinete do Secretário de Estado da Educação. https://dre.pt/application/ conteudo/107752620

ECHEVERRÍA, Beatriz; LÓPEZ-LARROSA, Sílvia; \& MENDIRI, Paula (2020). Aplicación de un programa de educación socio-emocional para alumnado de Primaria. Revista de Estudios e Investigación en Psicología y Educación, 7(2), 174-183. https://doi.org/10.17979/reipe. 2020.7.2.7101

FERNANDES, Natália (2019). Infância e o Direito à Educação: dos ditos aos interditos. Revista entreideias: educação, cultura e sociedade, 8 (2), 11-26. https://doi.org/10.9771/re.v8i2. 28749

GRAHAM, Anne, \& FITZGERALD, Robyn (2010). Progressing children's participation: Exploring the potential of a dialogical turn. Childhood, 17, 343-359. https://doi.org/10.1177/090 7568210369219 
HOHMANN, Mary, \& WEIKART, David (2011). Educar a criança. Lisboa: Fundação Calouste Gulbenkian.

LANSDOWN, Gerison (2010). The realization of children's participation rights: Critical reflections. In Barry Percy-Smith, \& Nigel Thomas (Eds.), A Handbook of Children and Young People's Participation: Perspectives from Theory and Practice (pp. 11-23). London: Routledge. https://doi.org/10.4324/9780203871072

LANSDOWN, Gerison (2011). Every child's right to be heard: A resource guide on the UN Committee on the rights of the child general comment No. 12. London: Save the Children UK. Disponível em: https://resourcecentre.savethechildren.net/library/every-childs-right -be-heard-resource-guide-un-committee-rights-child-general-comment-no-12

MäKITALO, Åsa (2016). On the notion of agency in studies of interaction and learning. Learning, Culture and Social Interaction, 10, 64-67. https://doi.org/10.1016/j.Icsi.2016.07.003

MASCADRI, Julia; BROWNLEE, Joanne LUNN; JOHANSSON, Eva; SCHOLES, Laura; WALKER, Sue; \& BERTHELSEN, Donna (2021). Children's perspectives on why and when teachers listen to their ideas: Exploring opportunities for participation in the early years of school. International Journal of Educational Research, 107. https://doi.org/10.1016/j.ijer.2021.101747

MORAES, Bianca Mota de; MOURAZ, Ana; \& COSME, Ariana (2017). A participação dos alunos nos projetos de melhoria das escolas. Revista de Estudios e Investigación en Psicología y Educación, (05), 316-321. https://doi.org/10.17979/reipe.2017.0.05.2824

O'KANE, Claire (2013). Children's participation in the analysis, planning and design of programmes: A guide for Save the Children staff. London: The Save the Children Fund. https://resourcecentre.savethechildren.net/node/7768/pdf/children_participation_in_p rogramming_cycle.pdf

OLIVEIRA-FORMOSINHO, Júlia, \& FORMOSINHO, João (2013). Pedagogia-em-Participação: A perspectiva educativa da associação da criança. Porto: Porto Editora.

OLIVEIRA-FORMOSINHO, Júlia, \& GÂMBOA, Rosário (orgs.). (2011). O trabalho de projeto na pedagogia-em-participação. Porto: Porto Editora.

SARMENTO, Manuel; FERNANDES, Natália; \& TOMÁS, Catarina (2019). Figuras da criança na sociologia da infância em Portugal. Sociedad e Infancias, 1, 39-59. https://doi.org/10. $5209 / \mathrm{SOCl} .56363$

SHERIDAN, Sonja, \& SAMUELSSON, Ingrid Pramling (2001). Children's conceptions of participation and influence in preschool. Contemporary Issues in Early Childhood, 2(2), 169-194. https://doi.org/10.2304\%2Fciec.2001.2.2.4 
SILVA, Brigite, \& CRAVEIRO, Clara (2014). O portefólio como estratégia de avaliação das aprendizagens na educação de infância: Considerações sobre a sua prática. Revista Zeroa-Seis, 29, 33-53. https://doi.org/10.5007/1980-4512.2014n29p33

SOUSA, Joana, LOIZOU, Eleni, \& FOCHI, Paulo (2019). Participatory pedagogies: Instituting children's rights in day to day pedagogic development. European Early Childhood Education Research Journal, 27, 299-304. https://doi.org/10.1080/1350293X.2019.1608116

TOMÁs, Catarina (2007). Participação não tem idade: Participação das crianças e cidadania da infância. Contextos \& Educação, 22, 45-68. https://doi.org/10.21527/2179-1309.2007. $78.45-68$

UNICEF (1989). Convenção sobre os direitos da criança. Disponível em: https://www.unicef.pt/ actualidade/publicacoes/0-a-convencao-sobre-os-direitos-da-crianca/

VASCONCELOS, Teresa (2015). Do discurso da criança "no" centro à centralidade da criança na comunidade. Investigar em Educação, II, 4, 25-42. http://pages.ie.uminho.pt/inved/index. php/ie/article/view/96

VEIGA, Renata, \& FERREIRA, Manuela (2017). Entre as práticas pedagógicas e as culturas infantis: contributo para a compreensão da participação das crianças em um Jardim de Infância. Cadernos de Estudos Sociais, 32 (2), 11-29. https://periodicos.fundaj.gov.br/CAD/article/ view/1695

Fecha de recepción: 27 de septiembre de 2020. Fecha de revisión: 29 de marzo de 2021. Fecha de aceptación: 1 de abril de 2021. Fecha de publicación: 1 de julio de 2021. 


\section{Apêndice - Guiões das Entrevistas}

\section{I - Guião da Entrevista às Educadoras de infância}

Idade:

Anos de Serviço:

Grau de habilitação académica:

1. O que é para si a participação da criança?

2. Concorda com a participação da criança no processo de ensino aprendizagem? Porquê?

3. Que benefícios pode trazer para a criança a sua participação no processo de ensino aprendizagem?

4. E ao nível do grupo, que benefícios pode trazer a participação da criança?

5. De que forma é que a criança participa no processo de ensino-aprendizagem?

6. Ao nível das dimensões curriculares (espaço e materiais; tempo; interações; planificação e avaliação; projetos e atividades, organização de grupos) existe espaço para que as crianças possam participar? De que forma?

7. Que obstáculos encontra para incentivar a participação da criança no processo de ensino aprendizagem?

8. Que estratégias utiliza para ultrapassar esses obstáculos e incentivar a participação da criança?

Agradecimentos!

\section{II - Guião da Entrevista aos Professores}

Idade:

Anos de Serviço:

Grau de habilitação académica:

1. O que é para si a participação da criança?

2. Concorda com a participação do aluno no processo de ensino-aprendizagem? Porquê?

3. Que benefícios pode trazer para o aluno a sua participação no processo de ensino aprendizagem?

4. Ao nível das dimensões curriculares (espaço e materiais; tempo; interações; planificação e avaliação; projetos e atividades, organização de grupos) existe espaço para que os alunos possam participar? De que forma?

5. Que obstáculos encontra para incentivar a participação do aluno no processo de ensino aprendizagem?

6. Que estratégias utiliza para ultrapassar esses obstáculos e incentivar a participação dos alunos? 